\title{
AVALIAÇÃO QUANTITATIVA E QUALITATIVA DO CARDÁPIO DE UMA UNIDADE DE ALIMENTAÇÃO E NUTRIÇÃO DA REGIÃO NOROESTE DO RIO GRANDE DO SUL ${ }^{1}$
}

\author{
QUANTITATIVE AND QUALITATIVE EVALUATION OF \\ THE MENU OF A FOOD AND NUTRITION UNIT IN THE \\ NORTHWEST REGION OF RIO GRANDE DO SUL
}

\author{
Eduarda Dendena de Souza ${ }^{2}$, Claudia Miranda Anschau Schneider ${ }^{3}$ e \\ Grazielle Castagna Cezimbra Weis ${ }^{4}$
}

\section{RESUMO}

O planejamento do cardápio de uma unidade de alimentação e nutrição deve considerar aspectos qualitativos e quantitativos de modo a promover uma alimentação nutricionalmente balanceada para os comensais. O objetivo do estudo foi avaliar quantitativamente e qualitativamente o cardápio oferecido em um serviço de alimentação e nutrição de uma empresa privada da região noroeste do Rio Grande do Sul (RS). Foi avaliado o cardápio do almoço de dez dias alternados, nos meses de novembro e dezembro no ano de 2019. A composição nutricional média do cardápio foi comparada com os critérios estabelecidos pelo Programa de Alimentação do Trabalhador (PAT). Enquanto que a avaliação qualitativa foi realizada utilizando o método AQPC e, a partir da frequência de oferta no cardápio, os itens foram classificados como "ótimo", "bom", "regular", "ruim" ou "péssimo". O cardápio apresentou valor energético médio adequado (1007,92 $\pm 132,74 \mathrm{kcal})$, no entanto, não atendeu as recomendações do PAT, possuindo perfil hipoglicídico, hiperproteíco e hiperlipídico. A quantidade de sódio presente foi superior a ingestão diária recomendada (2437 $\pm 98,13 \mathrm{mg})$. A oferta de fibras mostrou-se satisfatória com elevada oferta de folhosos e frutas (n=10, 100\%, "ótimo"). A presença de frituras, bem como sua associação com doces, e a monotonia de cores das preparações foram classificadas como "bom". Em contrapartida, a elevada oferta de doces, carnes gordurosas e alimentos ricos em enxofre, foram classificados como "péssimo". O cardápio analisado na UAN apresenta inadequações, em ambos os aspectos, que podem vir a repercutir na condição de saúde dos trabalhadores.

Palavras-chave: Alimentação coletiva, Planejamento de cardápios, Promoção da saúde, Qualidade das refeições.

\section{ABSTRACT}

The menu planning of a food and nutrition unit should consider qualitative and quantitative aspects in order to promote a nutritionally balanced diet for diners. The objective of the study was to quantitatively and qualitatively evaluate the menu offered in a food and nutrition service of a private company in the northwest region of Rio Grande do Sul (RS). The lunch menu of ten alternate days was evaluated in the months of November and December in the year 2019. The average nutritional composition of the menu was compared with the established criteria by the Workers Food Program (PAT). While the qualitative assessment was carried out using the AQPC method and, based on the frequency of the offer on the menu, the items were classified as "great", "good", "regular", "bad" or "very bad". The menu had an adequate average energy value (1007.92 $\pm 132.74 \mathrm{kcal})$, however, it did not meet the PAT recommendations, having a low carbohydrate, high protein and lipid content profile. The amount of sodium present was higher than the recommended daily intake $(2437 \pm 98.13 \mathrm{mg})$. The supply of fibers was satisfactory with

${ }^{1}$ Trabalho oriundo do estágio curricular em Unidades de Alimentação e Nutrição.

${ }^{2}$ Acadêmica do Curso de Nutrição - Universidade Federal de Santa Maria. E-mail: dudadendena@gmail.com

${ }^{3}$ Colaboradora. Nutricionista. E-mail: claudianschau@yahoo.com.br

${ }^{4}$ Orientadora. Docente do Curso de Nutrição - Universidade Federal de Santa Maria. E-mail: grazielle.castagna@gmail.com 
a high supply of leafy fruits ( $n=10,100 \%$, "excellent"). The presence of fried foods, as well as their association with sweets, and the monotony of colors in the preparations were classified as "good". On the other hand, the high offer of sweets, fatty meats and foods rich in sulfur, were classified as "terrible". The menu analyzed at the UAN has inadequacies, in both aspects, which may have an impact on the health status of workers.

Keywords: Collective Feeding, Menu Planning, Health Promotion, Food Quality.

\section{INTRODUÇÃO}

O planejamento do cardápio de uma Unidade de Alimentação e Nutrição (UAN) é uma atividade complexa, na qual o profissional técnico responsável deve considerar as leis da alimentação, o estado de saúde do comensal, além dos hábitos, preferências e aversões alimentares, para auxiliar na melhoria da qualidade de vida e satisfação do usuário. O cardápio apresenta diferentes dimensões de qualidade, como nutricional, sensorial, cultural e higiênico-sanitária. Uma vez consideradas todas essas dimensões, consegue-se realizar uma avaliação mais ampla e completa da qualidade da refeição (GINAMI, 2011; PROENÇA, 2008).

A qualidade do cardápio de uma UAN é avaliada através de parâmetros qualitativos e quantitativos que devem ser mensurados em vários dias, com o intuito de verificar de forma mais fidedigna a adequação do cardápio. A UAN que atua no Programa de Alimentação do Trabalhador (PAT) deve oferecer uma alimentação quantitativamente balanceada em macro e micronutrientes conforme a Portaria Interministerial n66/2006 (VANIN et al., 2007; BRASIL, 2006).

Embora a composição nutricional seja um fator de relevância para melhorar a qualidade de vida do trabalhador, a oferta de um cardápio qualitativamente atrativo, considerando cor, sabor e textura, também consiste em um instrumento de educação alimentar e nutricional para os comensais, promovendo uma alimentação balanceada. Dessa forma, o método de Avaliação Qualitativa das Preparações do Cardápio (AQPC) permite analisar o cardápio de uma maneira mais ampla, abrangendo itens como presença de frituras, doces, carnes gordurosas, vegetais, frutas, alimentos sulfurados e variabilidade das cores das preparações (FERREIRA; VIEIRA; FONSECA, 2015; PROENÇA, 2008).

A adequação das refeições, tanto em aspectos quantitativos como qualitativos, é fundamental para melhorar a condição de saúde do trabalhador, uma vez que podem prevenir Doenças Crônicas não Transmissíveis (DCNT), como a obesidade e hipertensão arterial. Ainda, melhora o estado nutricional dos funcionários, e por consequência, contribui no desempenho de suas atividades e redução de acidentes de trabalho (CARLESSO; BALESTRIN, 2018).

Dessa forma, este estudo teve como objetivo avaliar quantitativamente e qualitativamente o cardápio oferecido em um serviço de alimentação e nutrição de uma empresa privada de um município da região noroeste do Rio Grande do Sul (RS). 


\section{MATERIAL E MÉTODOS}

Trata-se de um estudo descritivo, de caráter qualitativo e quantitativo, realizado nos meses de novembro a dezembro de 2019 em uma UAN de uma empresa privada localizada na região noroeste do Rio Grande do Sul (RS).

A UAN fornece em média 430 refeições diárias de almoço sob a forma de self-service. O cardápio é constituído por três tipos de saladas, três tipos de arroz; feijão; duas guarnições; um molho; e uma fonte proteica, contendo duas ou três opções distintas a escolha do consumidor; além de uma sobremesa, podendo ser fruta ou doce. Para o estudo, avaliou-se o cardápio do almoço durante dez dias alternados, de segunda-feira a sexta-feira (Quadro 1).

As porções foram estabelecidas pelo responsável técnico da Unidade, através da elaboração das Fichas Técnicas de Preparações (FTP), sendo ainda, a porção proteica estabelecida em conjunto com a empresa contratante. Ainda, a porção de sódio foi estabelecida através do acompanhamento da quantidade de sal adicionado nas preparações na elaboração.

Para o cálculo da composição nutricional do cardápio considerou-se a quantidade energética e de nutrientes como carboidratos, proteínas, gordura total, gordura saturada, fibras e sódio presentes. Posteriormente, realizou-se cálculo para verificar a média e o desvio-padrão do total de energia e nutrientes presentes no cardápio dos dez dias avaliados.

Quadro 1 - Cardápio analisado na Unidade de Alimentação e Nutrição de um município da região noroeste, RS.

\begin{tabular}{|c|c|}
\hline Dia & Preparações \\
\hline 1 & $\begin{array}{l}\text { Repolho roxo; cenoura; pepino; arroz branco; arroz temperado com orégano; arroz integral; feijão preto; couve refogada } \\
\text { com farofa; polenta; molho roti; steak de frango; omelete com tempero verde; cupim assado; banana; goiabada. }\end{array}$ \\
\hline 2 & $\begin{array}{l}\text { Alface com rúcula; tomate com cebola; rabanete; arroz branco; arroz com alho; arroz integral; feijão preto; macarrão com } \\
\text { bacon; quibebe; molho calabresa; bisteca suína; hambúrguer bovino; omelete de frios; maçã; torta de bolacha. }\end{array}$ \\
\hline 3 & $\begin{array}{l}\text { Alface com couve; repolho em conserva; abobrinha fatiada; arroz branco; arroz com cenoura; arroz integral; feijão carioca; } \\
\text { cenoura com chuchu e bacon; ravioli; molho madeira; lagarto assado; ovo grelhado; almôndegas; mamão; gelatina de morango. }\end{array}$ \\
\hline 4 & $\begin{array}{l}\text { Alface; repolho roxo; cenoura com tomate; arroz branco; arroz com alho; arroz integral; feijão preto; polenta frita; macarrão } \\
\text { ao alho e óleo; molho sugo; bife bovino; steak de frango; ovo grelhado; salada de fruta; doce de amendoim. }\end{array}$ \\
\hline 5 & $\begin{array}{l}\text { Alface com almeirão; cenoura; mix de grãos; arroz branco; arroz com curry; arroz integral; feijão preto; polenta; molho } \\
\text { rosé; couve-flor; pernil ao molho roti; steak de frango; omelete com tempero verde; laranja; creme de morango. }\end{array}$ \\
\hline 6 & $\begin{array}{l}\text { Alface; grão de bico; cenoura; arroz branco; arroz com orégano; arroz integral; feijão carioca; bolo salgado; ratatouille; } \\
\text { molho de vinho; bisteca suína; ovo cozido; sassami de frango; melão; gelatina de abacaxi. }\end{array}$ \\
\hline 7 & $\begin{array}{l}\text { Alface; salpicão; grão de trigo; arroz branco; arroz com curry; arroz integral; feijão preto; macarrão ao molho vermelho; abo- } \\
\text { brinha gratinada; molho rosé; hambúrguer bovino; steak de frango; omelete com tempero verde; banana; creme de baunilha. }\end{array}$ \\
\hline 8 & $\begin{array}{l}\text { Alface com almeirão; repolho roxo; pepino; arroz branco; arroz com curry; arroz integral; feijão preto; brócolis com } \\
\text { bacon; macarrão ao molho pesto; molho com calabresa; sassami de frango; omelete de frios; almôndegas; melão; sagu. }\end{array}$ \\
\hline 9 & $\begin{array}{l}\text { Alface com repolho; brócolis com cenoura; pepino com tomate; arroz branco; arroz com alho; arroz integral; feijão carioca; } \\
\text { batata frita; farofa com frutas cristalizadas; molho madeira; patinho; ovo grelhado; maçã, gelatina de pêssego. }\end{array}$ \\
\hline 10 & $\begin{array}{l}\text { Alface; pepino; tomate; arroz branco; arroz temperado com colorau; lentilha; brócolis no vapor; lasanha à bolonhesa; } \\
\text { molho sugo; steak de frango; iscas de fígado; ovo cozido; laranja e creme de amendoim }\end{array}$ \\
\hline
\end{tabular}


A composição nutricional do cardápio foi calculada através do software Calculadora Nutricional (Calcnut) no Excel utilizando a Tabela Brasileira de Composição de Alimentos (2011), através do per capita estabelecido pela unidade. Devido a UAN ofertar dois ou três tipos de pratos proteicos, o per capita para o cálculo dos cardápios foi obtido pela sua média. Para análise quantitativa dos cardápios, comparou-se os valores médios encontrados com as recomendações nutricionais exigidas pelo PAT, conforme a Portaria Interministerial nº6/2006.

A avaliação qualitativa das refeições foi realizada utilizando o método AQPC (VEIROS; PROENÇA, 2003; PROENÇA, 2008), o qual considera aspectos nutricionais e sensoriais, analisando as preparações de acordo com os seguintes critérios:

- Presença de hortaliça folhosa: considerou-se quando da presença de pelo menos uma hortaliça folhosa ofertada como salada;

- Presença de frutas;

- Monotonia de cores das preparações e dos alimentos: considerada quando três ou mais alimentos com cores iguais estavam presentes em um mesmo dia;

- Presença de alimentos sulfurados: considerada quando dois ou mais alimentos ricos em enxofre estavam presentes no cardápio. Considerou-se alimentos sulfurados como abobrinha, acelga, amendoim, batata doce, brócolis, couve, couve-flor, grão-de-bico, maçã, ovo, pepino, rabanete e repolho. O feijão, presente diariamente nas refeições, não foi considerado nesta análise;

- Presença de carnes gordurosas como prato principal: considerou-se como carnes gordurosas bisteca suína, pernil suíno, cupim e produtos cárneos industrializados (PHILIPPI, 2003);

- Oferta de doces como sobremesa: foram considerados doces e preparações doces balas, confeitos, bombons, chocolates e similares, bebidas lácteas, produtos de confeitaria com recheio e/ou cobertura, biscoitos e similares com recheio e/ou cobertura, doces em pasta, geleias de fruta;

- Aparecimento de frituras, isoladamente e associada com a oferta de doces;

- $\quad$ Técnicas de preparo e cocção.

Os itens analisados das preparações, a partir da sua frequência no cardápio, foram classificados em categorias como "ótimo" ( $\geq 90 \%)$, “bom” (75 a 89\%), "regular” (50 a 74\%), "ruim” (25 a 49\%) ou "péssimo" (<25\%), considerando os aspectos positivos (como a oferta de frutas e folhosos), e em “ótimo" ( $\leq 10 \%)$, "bom" (11 a 25\%), "regular" (26 a 50\%), "ruim" (51 a 75\%) ou "péssimo" (> 75\%), no que se refere aos aspectos negativos do cardápio (cores iguais, preparações ricas em enxofre, carne gordurosa, doce, fritura e a oferta de fritura associada a doce no mesmo dia) de acordo com metodologia proposta por Prado, Nicolettia e Faria (2013).

Os dados coletados foram tabulados, analisados com o auxílio do software Microsoft Office Excel, e expressos através da média e desvio padrão e em percentuais em relação ao número total de dias dos cardápios avaliados. 


\section{RESULTADOS E DISCUSSÃO}

Os resultados da análise quantitativa dos cardápios analisados durante os dez dias da pesquisa e o percentual de adequação dos nutrientes em comparação com os valores recomendados pelo PAT encontram-se na Tabela 1.

Tabela 1 - Análise da composição nutricional do cardápio de uma Unidade de Alimentação e Nutrição de um município da região noroeste do Rio Grande do Sul, no ano de 2019, comparada a recomendação do Programa de Alimentação do Trabalhador.

\begin{tabular}{|c|c|c|c|}
\hline Nutrientes e NDPcal\% & Média \pm DP* & Recomendação PAT** & Adequação (\%) \\
\hline Energia (kcal) & $1007,92 \pm 132,74$ & $600-800 \pm 400$ & $95,0-109,4$ \\
\hline Carboidratos (\%) & $38,32 \pm 4,22$ & 60 & $56,8-70,9$ \\
\hline Proteínas (\%) & $22,18 \pm 3,94$ & 15 & $121,7-174,1$ \\
\hline Gorduras totais (\%) & $39,53 \pm 4,91$ & 25 & $138,5-177,8$ \\
\hline Gorduras saturada (\%) & $10,49 \pm 1,80$ & $<10$ & $86,9-122,9$ \\
\hline NDPcal (\%) & $12,03 \pm 3,49$ & $6-10$ & $85,4-155,2$ \\
\hline Fibras (g) & $12,56 \pm 2,37$ & $7-10$ & $101,9-149,3$ \\
\hline Sódio (mg) & $2437 \pm 98,13$ & $720-960$ & $243,6-264,1$ \\
\hline
\end{tabular}

Verificou-se que as refeições apresentam valor energético médio adequado (1007,92 $\pm 132,74$ kcal), estando em concordância com a recomendação do PAT. No entanto, no que se refere a distribuição dos macronutrientes, os cardápios apresentaram característica hipoglicídica, hiperproteíca e hiperlipídica, o que gera preocupação. Destaca-se que existe uma mudança no padrão alimentar da população brasileira, devido ao consumo excessivo de macronutrientes, principalmente de gordura e açúcares simples, o que impacta no estado nutricional (MONTEIRO; CANNON, 2012). Ressalta-se ainda que o consumo desproporcional desses nutrientes além de não atender as exigências do PAT, eleva o custo das refeições e pode gerar agravos a saúde, independente do estado nutricional (DUARTE et al., 2015).

A oferta insuficiente de carboidratos nos cardápios analisados $(38,32 \pm 4,22 \%)$, apresentando adequação máxima de 70,9\%, consiste em um dos pontos mais críticos verificados, embora não seja uma realidade exclusiva da UAN analisada. Duarte et al. (2015) e Ferreira, Vieira e Fonseca (2015) em seus estudos analisando UAN de diferentes modalidades de gestão, participantes ou não do PAT, também identificaram a oferta insuficiente de carboidratos nos cardápios, com percentuais de adequação ainda inferiores aos nossos encontrados. Destaca-se que esse nutriente deve possuir o maior percentual de oferta no cardápio frente aos demais macronutrientes, de acordo com o PAT, tendo em vista sua função energética, o que deve ser priorizado para os trabalhadores (DUARTE et al., 2015). Assim, a deficiência da ingestão de carboidratos poderia prejudicar o desempenho dos trabalhadores (VANIN et al., 2007). 
O percentual de proteína e gordura total nos cardápios analisados encontra-se acima do recomendado, apresentando $22,18 \%$ e $39,53 \%$, respectivamente. Comparado com os valores preconizados pelo PAT, esses níveis apresentam-se até $70 \%$ acima dos valores estabelecidos. Salienta-se que a opção proteica oferecida na UAN em questão consiste em uma porção de $180 \mathrm{~g}$, o que pode contribuir com a elevada ingestão de ambos macronutrientes, pois a depender da origem do alimento, principalmente os de origem animal, o corte e a forma de preparo, podem influenciar a presença destes nutrientes em excesso (FERREIRA, VIEIRA e FONSECA, 2015). Destaca-se que o percentual de adequação máxima de gordura saturada também excedeu a recomendação (122,9\%), o que está relacionado com o aumento do risco de doenças cardiovasculares (PRÉCOMA et al., 2019).

Verifica-se que o NDPCal possuí variação no seu percentual de adequação mínimo e máximo. Em consequência da elevada oferta de proteína, a adequação máxima de NDPCal, de 155,2\%, foi superior ao recomendado pelo PAT. Destaca-se que a ingestão excessiva de proteínas está relacionada com o desenvolvimento de doenças renais e osteoporose (VILLA, MELO, SPINELLI, 2018).

A oferta de fibras foi maior que a quantidade recomendada pelo PAT. Embora seja um resultado positivo, pois a oferta de fibras está associada com a redução de doenças crônicas não transmissíveis e doenças cardiovasculares, deve-se atentar para o excesso de fibras na alimentação, uma vez que quanto maior a oferta de fibras, maior a presença de fatores antinutricionais, como os fitatos, os quais dificultam a absorção de minerais importantes para a saúde, como cálcio, ferro e zinco (FIGUEIREDO et al., 2009). Destaca-se que o cardápio da UAN em questão, apresenta oferta diária de alimentos ricos em fibras, estudos como de Savio et al. (2005) evidenciam que cardápios que apresentam baixa oferta de alimentos como feijão ou guarnição com vegetais, não conseguem atingir a recomendação de fibras.

Em relação ao sódio, verificou-se que os cardápios analisados apresentaram valores muito superiores aos recomendados pelo PAT, com percentuais de adequação superiores à $250 \%$, ou seja, mais que o dobro do valor preconizado. Apesar da unidade não apresentar saleiro sobre as mesas, observou-se a adição excessiva de sal na elaboração das preparações, sendo superior ao estabelecido nas FTP, juntamente com a presença de carnes ultraprocessadas no cardápio, como por exemplo o steak de frango, o qual era ofertado quase diariamente, corrobora com a elevada concentração desse micronutriente nos cardápios. A ingestão excessiva de sódio está relacionada com o aumento de risco de hipertensão arterial e incapacita temporariamente os trabalhadores (DUARTE et al., 2015; BRITO, SPINELLI, 2016). O excesso desse nutriente em preparações de UAN também foi evidenciado por Reinaldo, Resende e Anna (2017) e Salas et al. (2009), que encontraram valor de ingestão diária de sódio acima de $2000 \mathrm{mg}$, assim como o presente estudo. Tendo em vista que a Organização Mundial de Saúde (2012) preconiza a ingestão inferior a 2000 mg de sódio, a partir dos valores encontrados em nosso estudo, pode-se inferir que, somente com a refeição do almoço, os trabalhadores da UAN estariam ingerindo uma quantidade de sódio superior ao recomendado no dia. 
No que se refere à avaliação qualitativa dos cardápios analisados, os resultados encontram-se na tabela 2.

Tabela 2 - Análise qualitativa e classificação dos aspectos positivos e negativos dos cardápios da Unidade de Alimentação e Nutrição de um município da região noroeste do Rio Grande do Sul, no ano de 2019.

\begin{tabular}{lccc}
\hline \multirow{2}{*}{ Parâmetro } & \multicolumn{2}{c}{ Ocorrência } & \multirow{2}{*}{ Classificação } \\
\cline { 2 - 3 } & $\mathbf{N}$ & Frequência & \\
\hline Folhosos & 10 & $100 \%$ & Ótimo \\
Frutas & 10 & $100 \%$ & Ótimo \\
Ricos em enxofre & 10 & $100 \%$ & Péssimo \\
\hline Fritura & 2 & $20 \%$ & Bom \\
Doces & 10 & $100 \%$ & Péssimo \\
\hline Fritura associada a doce & 2 & $20 \%$ & Bom \\
Monotonia de cores & 2 & $20 \%$ & Bom \\
\hline Carnes gordurosas & 9 & $90 \%$ & Péssimo \\
\hline & Fonte: As autoras & \\
\hline
\end{tabular}

Em todos os cardápios analisadas observou-se a presença de folhosos ( $\mathrm{n}=10,100 \%)$, sendo o resultado classificado como "ótimo", uma vez que consiste em um aspecto positivo de um cardápio. Em quatro dias analisados teve-se a oferta de até duas opções de folhosos na salada. Resultados semelhantes foram encontrados nos estudos de Casaril (2020), Ygnatios, Lima e Pena (2017) e Fassina, Leonhardt e Kerber (2019), em que também se observaram a presença de folhosos como alface lisa, alface crespa, almeirão, repolho e rúcula.

Devido a UAN estudada oferecer duas opções de sobremesa, a oferta de doces e frutas ocorreu em todos os dias analisados $(n=10,100 \%)$. A frequência de oferta de frutas encontrada na UAN consiste em um item "ótimo", enquanto que a oferta de doces foi classificada como "péssimo", tendo em vista ser um aspecto negativo de um cardápio. Destaca-se que a oferta simultânea de doces e frutas, foi estabelecida de maneira contratual, e faz com que o comensal tenha poder de escolha, o que também foi verificado no estudo de Fassina, Leonhardt e Kerber (2019). Dessa forma, é importante realizar ações de educação alimentar e nutricional na unidade, pois a oferta de frutas não significa necessariamente a ingestão pelo comensal. A oferta elevada de doces foi uma realidade observada em estudos como de Casaril (2020) e Ygnatios, Lima e Pena (2017), o que contribuí com o aumento da ingestão calórica, e consequentemente, com o desenvolvimento de sobrepeso, obesidade e demais comorbidades. Destaca-se que, apesar de não ser analisado neste estudo, a UAN oferece suco artificial de maneira ilimitada para os comensais. A bebida, constituída principalmente de açúcares simples, está associada com o desequilíbrio hormonal, dislipidemias e obesidade (SILVA, 2019). Apesar disso, a unidade apresentou variedade em relação as frutas ofertadas, o que garante a ingestão de diferentes vitaminas, minerais e fibras, e que contribui com a saúde do trabalhador (FASSINA; LEONHARDT; KERBER, 2019).

No que se refere a presença de frituras, verificou-se a oferta de preparações fritas em apenas dois dias, correspondendo a $20 \%$ dos dias analisados. De igual forma, a oferta de doces e frituras 
ocorreu em dois dias (20\%), apesar de ser ambos aspectos negativos, classificaram-se como "bom", devido à baixa frequência de oferta. O mesmo percentual foi encontrado por Ygnatios, Lima e Pena (2017), que apesar de avaliar qualitativamente o cardápio de uma escola, elencam a presença de fornos industriais como aliados para variar as técnicas de preparo e melhorar o valor nutricional dos alimentos, o que também foi observado na unidade de produção em questão. A baixa oferta de preparações fritas reduz a ocorrência de desconforto gástricos nos comensais, uma vez que durante o processo de fritura ocorre alteração da estrutura das gorduras, podendo levar a formação de substâncias que irritam a mucosa gástrica. Além disso, a baixa frequência de frituras associadas a doces, reduz os riscos de desenvolvimento de doenças crônicas (CASARIL, 2020).

Referente a outros aspectos negativos do cardápio, foi possível observar que os itens de alimentos ricos em enxofre e carnes gordurosas apresentaram elevada frequência no cardápio, classificados como "péssimo". Em todos os dias analisados observou-se a presença de alimentos ricos em enxofre, variando entre três até quatro preparações, além da preparação do feijão. A elevada ocorrência de alimentos sulfurados também foi observada por Viana e Monteiro (2016), que sugerem que a oferta deve ser limitada devido a sensação de desconforto gástrico que o consumo excessivo desses alimentos pode causar ao comensal.

Quanto a presença de carne gordurosa $(n=9,90 \%)$, entre as diferentes opções proteicas ofertadas nos cardápios, quase diariamente verificou-se a presença de produtos cárneos industrializados, que além de apresentarem elevado teor de gordura na sua composição, também apresentam alto conteúdo de sódio (Tabela Brasileira de Composição dos Alimentos, 2011). Além disso, a nova edição do Guia Alimentar para a População Brasileira preconiza que o consumo de alimentos ultraprocessados deve ser evitado, tendo em vista que apresentam uma composição nutricional desbalanceada (BRASIL, 2014). Nas unidades de alimentação e nutrição, comumente são utilizadas carnes gordurosas devido ao baixo custo e melhor aceitação, quando comparado com carnes magras. Assim, o responsável técnico deve planejar o cardápio de modo a limitar a oferta e controlar a associação com doces. Sabe-se que a gordura pertencente aos alimentos de origem animal são do tipo saturada e ricas em colesterol, o que favorece o risco de doenças cardiovasculares. Da mesma maneira, a associação de carnes gorduras com a oferta de doces está relacionada com o desenvolvimento de aterosclerose (CASARIL, 2020; FASSINA; LEONHARDT; KERBER, 2019).

No que se refere as opções proteicas ofertados na UAN, das 29 preparações proteicas produzidas nos dez dias analisados, a figura 1 e figura 2 demonstram os tipos e as técnicas de preparo realizadas na Unidade de Alimentação e Nutrição avaliada. 
Figura 1 - Frequência das opções proteicas utilizados como prato principal da Unidade de Alimentação e Nutrição de um município da região noroeste do Rio Grande do Sul, no ano de 2019.

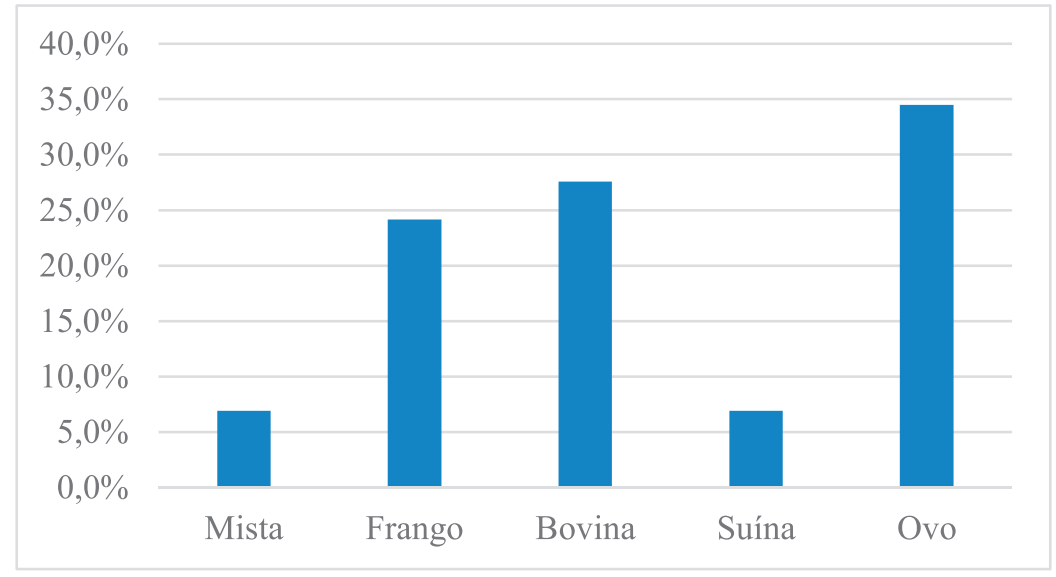

Fonte: As autoras.

Verifica-se que a UAN apresentou variedade quanto as opções proteicas oferecidas, com cinco tipos. O ovo apresentou a maior porcentagem de prato proteico oferecido, presente em todas as refeições e representando $34,9 \%$ do total de opções proteicas oferecidas. A carne do tipo bovina apresentou o segundo maior percentual, seguido da carne de frango, representando $27,6 \%$ e $24,1 \%$, respectivamente. As carnes que apresentaram menor percentual de oferta foram do tipo suína e mista, ambas com $6,9 \%$ de oferta. Quando comparado ao estudo de Barrozo e Mendonça (2015), verifica-se diferença em relação as opções proteicas oferecidas entre as UANs, o que é esperado, uma vez que características culturais e regionais influenciam e devem ser consideradas no momento da elaboração do cardápio (NASCIMENTO et al., 2020).

Figura 2 - Métodos de cocção utilizados no preparo do prato principal da Unidade de Alimentação e Nutrição de um município da região noroeste do Rio Grande do Sul, no ano de 2019.

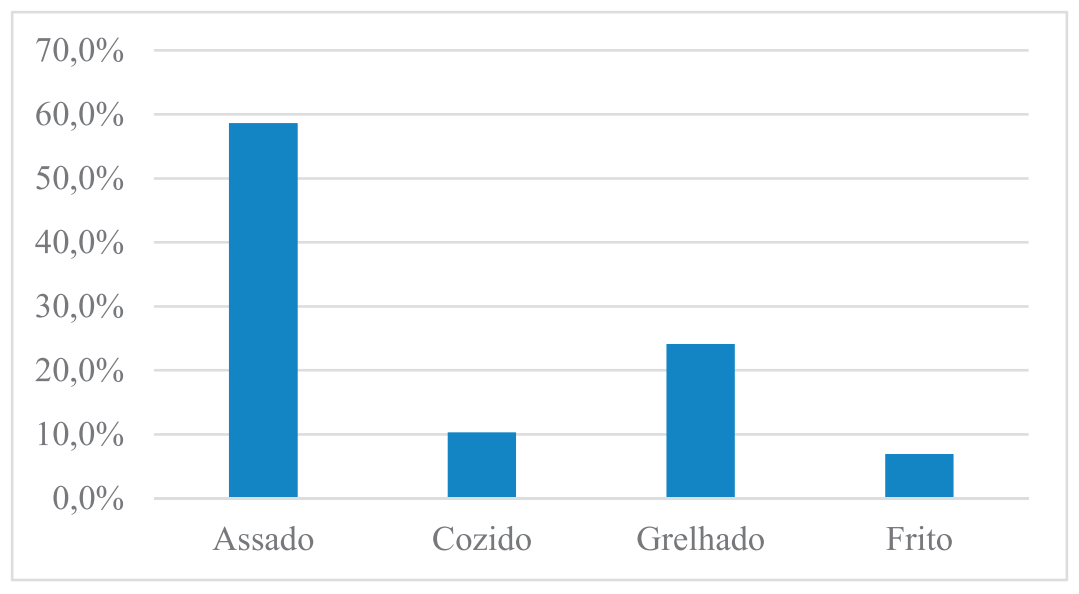

Fonte: As autoras.

Em relação a técnica de preparo das opções proteicas, verificou-se que a técnica assada foi a mais aplicada na unidade, correspondendo a 58,6\%. Na sequência, conforme a ocorrência, foram as preparações grelhadas, cozidas e fritas, representando $24,1 \%, 10,3 \%$ e $6,9 \%$, respectivamente. 
Destaca-se que a carne bovina, um dos tipos utilizados com maior frequência, pode apresentar elevado percentual de gordura a depender do corte utilizado. Na UAN em questão, o preparo das carnes bovinas foi realizado predominantemente utilizando calor a seco, o que é recomendado para a obtenção de preparações mais saudáveis (BARROZO; MENDONÇA, 2015). Além disso, os métodos de cocção para pratos principais que utilizam calor a seco apresentam boa aceitação pelos comensais.

Referente a análise de cores do cardápio, tendo em vista a grande variedade de preparações ofertadas, apenas dois dias do período analisado apresentaram três ou mais alimentos com cores iguais no cardápio ( $\mathrm{n}=2,20 \%$ ), sendo esse item classificado como "bom". A reduzida variabilidade de cores nas preparações influencia na alimentação, uma vez que a diversidade de cores torna a alimentação atrativa e prazerosa, garantindo a ingestão de diversos nutrientes (VEIROS; PROENÇA, 2003).

\section{CONCLUSÃO}

Os resultados obtidos permitiram concluir que o cardápio analisado na UAN, tanto em relação ao aspecto qualitativo quanto quantitativo apresenta algumas inadequações. $\mathrm{O}$ fato de quantitativamente o cardápio não estar em concordância com os parâmetros nutricionais estabelecidos pelo Programa de Alimentação do Trabalhador, especialmente no que se refere a oferta de carboidratos, proteínas, gorduras e sódio, pode influenciar na condição de saúde dos trabalhadores. Qualitativamente, a avaliação do cardápio mostrou alta oferta de folhosos e frutas, e baixa frequência de frituras e monotonia de cores diariamente na UAN, o que são aspectos positivos no cardápio. Entretanto, verificou-se elevada presença de carnes gordurosas, alimentos ricos em enxofre e doces nos almoços avaliados, indicando a necessidade de ajustes a serem realizados no cardápio de modo a oferecer refeições nutricionalmente mais balanceadas aos trabalhadores.

Dessa maneira, a aplicação periódica de métodos para avaliação do cardápio é importante para diagnosticar sua adequação e planejar possíveis alterações no cardápio priorizando sempre pela promoção da saúde do trabalhador. Além disso, devido ao almoço ser de grande importância para os trabalhadores, e o mesmos possuírem poder de escolha em relação aos alimentos oferecidos, é necessário desenvolver atividades de educação alimentar e nutricional para promover bons hábitos alimentares.

\section{REFERÊNCIAS}

BARROZO, A. L. P.; MENDONÇA, K. A. N. Análise qualitativa de preparações de cardápios de uma Unidade de Alimentação e Nutrição. Universitas: Ciências da Saúde, v. 13, n. 2, p. 87-92, 2015. 
BRASIL. Ministério do Trabalho e Emprego. Portaria Interministerial no 66 de 25 de agosto de 2006. Altera os parâmetros nutricionais do Programa de Alimentação do Trabalhador-PAT. Diário Oficial da União, Brasília, DF, p. 165, 2006.

BRASIL. Ministério da Saúde. Secretaria de Atenção à Saúde. Departamento de Atenção Básica. Guia Alimentar para a População Brasileira. 2. ed. Brasília: Ministério da Saúde, 2014.

CARLESSO, L. C.; BALESTRIN, M. B. Análise quantitativa e qualitativa do cardápio oferecido aos funcionários beneficiados pelo Programa de Alimentação do Trabalhador-PAT em um frigorífico situado em Campos Novos - Santa Catarina. Anuário Pesquisa e Extensão Unoesc Videira, v. 3, p. e19228-e19228, 2018.

CASARIL, K. B. P. B. Avaliação qualitativa das preparações do cardápio de uma unidade de alimentação e nutrição de Francisco Beltrão/PR. Nutrição Brasil, v. 19, n. 1, p. 9-15, 2020.

BRITO, A. M. O.; SPINELLI, M. G. N. Oferta de sódio oriundo de alimentos industrializados em restaurantes institucionais. DEMETRA: Alimentação, Nutrição \& Saúde, v. 11, n. 2, p. 321-336, 2016.

DUARTE, M. S. L. et al. Qualidade do almoço de trabalhadores segundo o Programa de Alimentação dos Trabalhadores e o índice de Qualidade da Refeição. Segurança Alimentar e Nutricional, v. 22, n. 1, p. 654-661, 2015.

FASSINA, P.; LEONHARDT, M. B.; KERBER, M. Análise qualitativa das preparações do cardápio de duas unidades de alimentação e nutrição. Arquivos de Ciências da Saúde, v. 26, n. 3, p. 153-157, 2019.

FERREIRA, M. S. B.; VIEIRA, R. B.; FONSECA, K. Z. Aspectos quantitativos e qualitativos das preparações de uma Unidade de Alimentação e Nutrição em Santo Antônio de Jesus, Bahia. Nutrivisa: Revista de Nutrição e Vigilância em Saúde, v. 2, n. 1, p. 22-27, 2015.

GINAMI, V.C. Avaliação da qualidade nutricional, sensorial e cultural de cardápios populares. 2011. 131p. Tese (Doutorado em Nutrição Humana) - Curso de Pós-Graduação em Nutrição Humana, Universidade de Brasília, Brasília, 2011.

MONTEIRO, C.; CANNON, G. The impact of transnational "big food" companies on the South: a view from Brazil. PLoS Medicine, v. 9, n. 7, p. e1001252, 2012. 
NASCIMENTO, M. C. F. et al. Índice de aceitabilidade e resto ingesta em unidade de alimentação e nutrição: estudo de caso no Ifes campus Santa Teresa-Brasil/Acceptance index and rest ingesta in food and nutrition unit: case study at the Ifes campus Santa Teresa-Brazil. Brazilian Journal of Health Review, v. 3, n. 2, p. 1868-1880, 2020.

ORGANIZAÇÃO MUNDIAL DE SAÚDE. Diretriz: Ingestão de Sódio para adultos e crianças. Geneve, 2012. Disponível em: https://bit.ly/2Kr321c. Acesso em 26 mai. 2020.

PHILIPPI, S.T. Nutrição e Técnica Dietética. 1 ed. São Paulo: Manole, 2003.

PRADO, B. G.; NICOLETTI, A. L.; FARIA, C. S. Avaliação qualitativa das preparações de cardápio em uma unidade de alimentação e nutrição de Cuiabá-MT. Journal of Health Sciences, v. 15, n. 3, 2013.

PROENÇA, R. P. C. Qualidade nutricional e sensorial na produção de refeições. 3. ed. Florianópolis: UFSC, 2008.

PRÉCOMA, D. B. et al. Atualização da Diretriz de Prevenção Cardiovascular da Sociedade Brasileira de Cardiologia: 2019. Arquivos Brasileiros de Cardiologia, v. 113, n. 4, p. 787-891, 2019.

REINALDO, J. M.; RESENDE, A. Sá; ANNA, M. S. L. S. Prevalência de hipertensão arterial e avaliação da ingestão de sódio em uma unidade de alimentação e nutrição. Revista da Associação Brasileira de Nutrição, v. 8, n. 1, p. 58-63, 2017.

SAVIO, K. E. O. et al. Avaliação do almoço servido a participantes do programa de alimentação do trabalhador. Revista de Saúde Pública, v. 39, p. 148-155, 2005.

SALAS, C. K. T. S. et al. Teores de sódio e lipídios em refeições almoço consumidas por trabalhadores de uma empresa do município de Suzano, SP. Revista de Nutrição, v. 22, n. 3, p. 331-339, 2009.

SILVA, D. C. G. et al. Consumo de bebidas açucaradas e fatores associados em adultos. Ciência \& Saúde Coletiva, v. 24, p. 899-906, 2019.

TACO, NEPA. Tabela brasileira de composição de alimentos. 4 ed. Campinas: NEPA UNICAMP, 2011.

VANIN, M. et al. Adequação nutricional do almoço de uma unidade de alimentação e nutrição de Guarapuava-PR. Revista Salus, v. 1, n. 1, 2007. 
VEIROS, M. B.; PROENÇA, R. P. C. Avaliação qualitativa das preparações do cardápio em uma unidade de alimentação e nutrição-método AQPC. Nutrição em Pauta, v. 11, n. 62, p. 36-42, 2003.

VIANA, M. B.; MONTEIRO, M. R. P. Avaliação Qualitativa das Preparações do Cardápio em uma unidade produtora de refeições de Belo Horizonte/MG. Nutrição Brasil, v. 15, n. 1, p. 36-41, 2016.

YGNATIOS, N. T. M.; LIMA, N. N.; DAS GRAÇAS PENA, G. Avaliação qualitativa das preparações do cardápio de uma escola privada em um município do interior de Minas Gerais. Revista da Associação Brasileira de Nutrição, v. 8, n. 1, p. 82-89, 2017.

VILLA, S. R.; MELO, V.; SPINELLI, M. G. N. Oferta de proteína e sódio dos pratos proteicos em refeições de uma unidade de alimentação. Revista Univap, v. 24, n. 46, p. 117-128, 2018. 
